\title{
Factors related to wife-battering; a medico-legal analysis
}

\author{
Vidanapathirana M \\ Department of Forensic Medicine, Faculty of Medical Sciences, University of Sri Jayewardenepura, Sri Lanka
}

Correspondence: Dr. Muditha Vidanapathirana

Tel: +94772988227; Fax: 0094112801480; e-mail: mudithavidana@gmail.com

\begin{abstract}
Introduction: Wife-battering has not been adequately studied from a medico-legal aspect in Sri Lanka. This study was carried out to describe the types of abuses as well as to explore the consequences, management strategies and impact on criminal justice system.
\end{abstract}

Methods: A descriptive study involving 4838 Medico-Legal Examination Forms (MLEFs) reported to a tertiary care hospital in Colombo from January 2011 to December 2012 was conducted. Out of 4838 MLEFs, 116 reports of wife battering were studied. The judicial responses of all cases were studied from relevant police records.

Results: Forty one percent of victims were less than 30 years of age. Majority (87\%) had faced repeated incidents. All had been abused verbally and psychologically. All had physical, psychological or sexual consequences. Majority (60\%) had head injuries. Eighty seven percent were non-grievous injuries. Twenty eight percent who directly reported to hospital, refused informing police. The judicial responses were completed in all except two attempted murder cases.

Conclusions: Wife-battering is not uncommon in Sri Lanka and many have faced repeated events. The pattern of injuries and their consequences are significant and the vigilance of clinicians is needed to identify them. The victim's choice in taking legal action should be retained. Activation of criminal justice system was mainly based on interpretation of injuries.

Keywords: Wife battering, Medico-legal analysis, Sri Lanka

\section{Introduction}

Wife-battering in Sri Lanka has not been studied in details from a medico-legal point of view. A study done by Saravanapavananthan (1982) mainly described the weapons and injuries associated with wife battering (1). A study by Samarasekera (1988) described associated factors and injury patterns of the survivors of wife- battering (2).

Though the life time prevalence of wife battering was $20-60 \%$ in 2011 in Sri Lanka (3), only few victims seem to have reported to authorities. Majority of the victims of wife battering may have presented to hospitals with various other unrelated complains and may have gone unnoticed. Therefore, 'wife battering risk assessment tools' must be available to the clinicians to identify victims. Further, an evidence-based intervention program is needed for holistic management, to reduce morbidity and mortality, and to strengthen the criminal justice system to curb this issue.

The current study was designed to describe the various types of abuses, their consequences and risk factors, to identify the factors important for the management and to describe the impact on criminal justice system.

\section{Methods}

A descriptive, cross-sectional study was conducted at a tertiary care hospital in Colombo from $1^{\text {st }}$ January 2011 to $31^{\text {st }}$ December 2012. 
All (4838) Medico-Legal Examination Forms (MLEFs) of five consented forensic medical practitioners out of nine were perused to identify reports of wife battering. Demographic factors, factors related to the incidents were collected using a data collection form. Data of husbands were also extracted from the MLEFs. The judicial responses were studied from relevant police records.

As secondary sources, BHTs, medical reports, police reports and court records, were also used.

\section{Results}

Out of 4838 MLEFs, 116 (2.4\%) wife batting cases were identified. Age of the victims ranged from 18-72 years. The median age was 32 years and IQR was 27-39 years. Forty one percent $(n=48)$ of the victims were less than 30 years. Age distribution is shown in Table 1.

Table 1: Age distribution

\begin{tabular}{ccc}
\hline Age groups & Frequency & Percent \\
\hline = $<30$ years & 48 & 41 \\
31 - 40 years & 45 & 39 \\
41 - 50 years & 17 & 15 \\
51 - 60 years & 05 & 04 \\
$>60$ years & 01 & 01 \\
\hline
\end{tabular}

Age of the husbands ranged from 20-73 years. The median age was 36 years and IQR was $30-41$ years. Forty percent $(n=47)$ were between $31-40$ years. The mean age difference between the 'husbands' and victims was 3 years.

According to the life time prevalence, 13\% (15) had faced a single incident, $28 \%$ (32) 2-10 incidents and $59 \%(69)$ more than 10 incidents. Repeated incidents ( 2 or more) had been faced by $87 \%(n=101)$.

Fifty six percent assaults occurred during daytime and $95 \%$ at home. Minor physical assaults included pushing (100\%) and slapping (95\%). Major physical assaults included punching/kicking (52\%), strangling $(09 \%)$, assault with a blunt weapon such as club, bed pole, firewood, broomstick etc (73\%, $\mathrm{n}=84$ ) and cut, stabbed or burned with a hot iron $(06 \%)$.

Of 116 incidents reported attacks targeting head was

reported in 70 instances, upper or lower limbs in 65 times and trunk in 28 times.

Abrasions (Figure 1), contusions (Figure 2) and lacerations (Figure 3) were considered as 'minor injuries'. Most common minor injury was contusion (69\%). Black eyes (Figure 4), fractures (Figure 5), slap marks (Figure 5), tramline contusions, ear injuries, bite marks and burns were considered as 'major injuries'. The most common major injury was black eye $(15 \%)$.

Majority (87\%) had non-grievous injuries and the severity of injuries is shown in Table 2 .

Table 2: Severity of injuries

\begin{tabular}{lcc}
\hline \multicolumn{1}{c}{ Severity } & Frequency & Percent \\
\hline No injuries & 03 & 02 \\
Non-Grievous & 101 & 87 \\
Grievous injuries & 10 & 09 \\
Endanger life & 01 & 01 \\
$\begin{array}{l}\text { Fatal in the ordinary } \\
\text { course of nature }\end{array}$ & 01 & 01 \\
\hline Total & $\mathbf{1 1 6}$ & $\mathbf{1 0 0}$ \\
\hline & & \\
& & \\
& &
\end{tabular}

Figure 1: Abrasions

Figure 2: Contusions

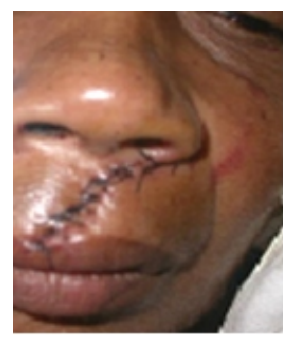

Figure 3: Lacerations

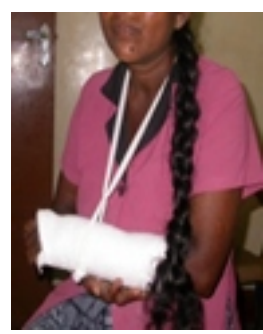

Figure 5: Fracture

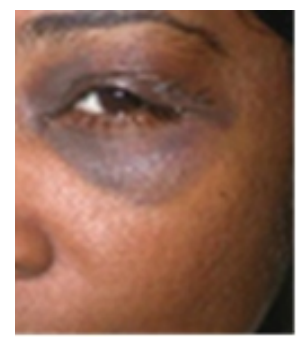

Figure 4: Black eye

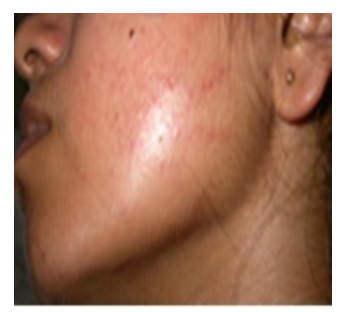

Figure 6: Slap Mark eye 
Majority (96\%) of the victims were married and 05 were living together. Seventy two percent of victims were unemployed. Majority (63\%) lived within the municipal council limits (considered as urban) and the rest were rural. Eighty five percent had one or more children and 17 did not have children. One victim was reported to have an extra-marital affair.

Seventy eight percent husbands were unemployed or temporally employed. Sixty nine percent of husbands consumed alcohol regularly, 02 were drug addicts and 03 had extra-marital affairs.

All victims were verbally and psychologically abused and in 17 victims their daily activities were controlled by husbands. Sexual abuse included refusal of sexual activities by husband (06) and in 02 instances purposely deprived of sexual intercourse for 2 years. One husband assaulted wife when she refused to have sex.

As the consequences of abuse, victims suffered pain, blurring of vision, hearing loss, mobile teeth, etc and 08 victims had physical disabilities such as fractured teeth, deformed fingers, facial scars and hearing impairment. Eight victims attempted suicide. Though all had some form of psychological or emotional effect, 03 were referred to psychiatrists and 04 were referred to protective services such as Children and Women's bureau or to volunteer organizations. There were no referrals to social services. Three children avoided schooling.

Regarding retaliation, 24 retaliated verbally, 23 assaulted back, 18 with body parts and 05 with blunt weapons.

The impact of the submission of duly filled police copy of the MLEF on the criminal justice system was also analysed.

Three "no injuries" and 94 non-grievous injuries due to blunt weapons were reported under 'Law of voluntarily causing hurt' and were referred to mediation board. Of them, 08 with risk to life and multiple incidents were reported under "prevention of domestic violence Act" and obtained "protection orders" and were referred for "mandatory family counseling".

Non-Grievous injuries due to sharp force trauma (07) were reported under 'Law of voluntarily causing hurt by dangerous weapons'. Five (05) were given suspended sentences and 02 were settled by the mediation board.
Ten (10) grievous hurt cases were charged under 'Law of voluntarily causing grievous hurt' and punished with suspended sentences. Of them 02 were charged under DV act and the victims were offered "protection orders" and "mandatory family counseling".

The 'Endangering life' (01) and 'Fatal in the ordinary course of nature' (01) were indicted at high courts under 'Law of attempt to murder' and were awaiting trial.

Out of $64(55 \%)$ who directly got admitted to hospital, 18 refused informing police.

\section{Discussion}

In this study, the prevalence of wife-battering among the reported medico-legal cases was $2.4 \%$. In Sri Lanka, life time prevalence of wife battering is 20$60 \%$ (3). This indicates either the victims are reluctant to report the authorities or the clinicians are unable to recognize the victims. Development of an evidence-based risk assessment tool for wife battering will improve this situation.

Similar to the findings of Hofner et al. (2005) (4), the victims were younger. According to Roy (1981), $75 \%$ of the husbands were between $26-50$ years (5) and in this study too, majority were between $30-50$ years.

The difference of ages of victim and 'husband' was about 03 years. According to Lawoko et al., (2007) the age gap between the victim and husband has relevance to the type of abuse. When the age gap of the couple is less than 10 years, more sexual violence was reported and when the age gap is equal or less than 03 years more physical violence was reported than the couples with age gap more than 04 years (6).

MacLeod (1980) showed wife battering is almost equal in rural and urban households (7). Contrary to that, in this study, majority were urban families. One possible explanation may be the location of this tertiary care hospital in an urban area.

Similar to a study done by Chan, Chiu and Chiu in Hong Kong (8), higher proportion of victims were unemployed and therefore, they were depended on husbands. Similar to Koenig et al. (9), few were unmarried.

Linda and walker (1989) observed majority of events to occur at night (10). Contrary to that, in this study, 
majority occurred during the day time. This discrepancy needs some examination. In this study, $78 \%$ husbands were without a permanent occupation and would have stayed at home during the day time.

Similar to Saravanapavananthan (1982) (1) there was no intention of the husband to cause severe injuries and majority were non-grievous.

The most common site of injury was the head and similar to Saravanapavananthan's observations (1) the most common significant injury was black eye.

Similar to MacLeod (7), majority faced more than one episode of assaults. Ideally the number of episodes should have been converted to a rate by dividing the number of incidents by total period of time.

Studies done by Straus and others (2001) in USA, found that $82 \%$ of women use weapons against men and $25 \%$ men use weapons against women (11). Contrary to that, very few victims used weapons against men. Cultural differences may have contributed to the different observations we made in the current study.

Similar to study done by Kraanen and others (2013) (12), majority of husbands consumed alcohol regularly and it had a statistically significant association with the number of incidents $(\mathrm{p}<0.01)$. Similar to study done by Tsui et al (13), only few husbands were drug addicts.

Though Koenig et al. (2006) found that having an extra-marital relationship is associated with increase incidences of wife battering (9), in this study, one victim reported an extra-marital affair. This low figure may not reflect the true situation of the extramarital affairs of Sri Lankan married women and may be due to the fact that the victims are reluctant to admit an extra-marital affair due to social stigma.

In psychological abuse, similar to Koenig and others (9), the victims continued to suffer the effects of controlling behaviour of the husband. Similar to Hofner and others (5), a woman's rage was directed toward herself in the form of suicidal attempts or towards her children. Few children turned violent and some stopped schooling. Similar to Knapp (14), violence or threat of violence limited a woman's ability to negotiate safer sex with her partner.

It is believed that neither short or nor longer custody arrests are effective in curbing wife battering especially in the long run (15). In Sri Lanka, most cases were settled by non-custodial methods such as mediation boards or suspended sentences.

In USA, to rehabilitate the perpetrators, a special programme called 'Battering Intervention and Prevention Program' (BIPP) (16) is used and individual counseling is done. Similarly, under DV act, 'Mandatory family counseling', is done in Sri Lanka.

It was found that the activation of different responses of criminal justice system in wife battering is mainly based on the medicolegal opinion on injuries. The cases reported as 'no injuries' or 'non-grievous' were referred to mediation board and cases reported under grievous hurt, endangering life or fatal in the ordinary course of nature were not referred to mediation board.

Medico-legal opinion can be used to decide whether to request 'protection order' or not. In this study, only few such requests had been made and this highlights the importance of raising the awareness among community as well as police officers to request more and more protection orders on DVAct (17).

Currently, the main objective of the medico-legal examination is to collect evidence from victims for the purpose of prosecution of the husbands in court of law. Most victims had consequences due to physical, psychological or sexual abuses but few were referred to psychiatrist or counseling, and none to social services. Health care provider should not consider the victim as a "case" but as a "member of a family" and adopt multidisciplinary approach. Victims need 'emotional support' to reduce recurrent morbidity and mortality. It is important to refer all victims of wife battering, in government as well as private sector to a 'Health Care Provision Centre'/ 'Mithuru Piyasa' at the nearest hospital for counseling, befriending and holistic management.

We need to change our attitudes towards these victims. Out of 64 direct admissions, 18 requested the forensic medical practitioner not to inform police. We are bound to uphold the victims' rights of self-determination. Adult, sound mind, victims of criminal cases has a right to refuse informing to police. Wife battering has not been listed under the offences that public should give information mandatorily (section 21 of the criminal procedure code of Sri Lanka) (18). Therefore, health care providers are not bound to report such violence to police or magistrate without victim's consent. The 
survivor's choice in initiating legal action should be retained considering the implications of family disputes.

In conclusion, when providing medico-legal services, need of focusing beyond satisfying the legal requirement is reiterated. Evidence-based interventions should be arranged to reduce the risk to life and it is important to establish "Health Care Provision centres / Mithuru Piyasa" in each hospital.

\section{Acknowledgements}

Dr. D.S.K. Karunanayake, the Registrar in Forensic Medicine, University of Sri Jayewardenepura, Dr. N.D. Ruchira and Dr. H.K.R. Sanjeewa, Postgraduate trainees and Dr. H. Suffian at the Office of the Judicial Medical Officer, Teaching Hospital, Colombo South for collection of samples.

\section{References}

1. Saravanapavananthan N, Medico Legal Aspects of Injuries. Jaffna: St. Joseph's Catholic Press, 1982: 120-2.

2. Samarasekera A, Wife battering and some of its social and medico-legal aspects, Paper presented at the $102^{\text {nd }}$ anniversary academic sessions of Sri Lanka Medical Council. 1988.

3. Perera G, Jayasuriya, Review of Research Evidence on Gender Based Violence (GBV) in Sri Lanka, W.s.H. Committee, Editor 2011, Sri Lanka Medical Association.

4. Hofner MC, Python NV, Martin E, Gervasoni JP, Graz B, Yersin B. Prevalence of victims of violence admitted to an emergency department. Emergency Medicine Journal 2005; $22: 481-5$.

5. Roy M. "Four Thousand Partners in Violence: a Trend Analysis", in Maria Roy, Ed: The Abusive Partner: An Analysis of Domestic Battering. New York: Van Nostrand Reinhold Company, 1982.

6. Lawoko S, K Dalal, L Jiayou, B Jansson. Social inequalities in intimate partner violence: A study of women in Kenya. Violence and Victims 2007; 22(6): 773-84.

7. MacLeod L. Wife Battering in Canada: the Vicious Cycle, Hull, Quebec: Canadian Government Publishing Centre, 1980: 7: 32-3.
8. Chan, KL, Chiu MC, Chiu LS. Study on child and spouse battering. Overall report (Part one). Social Welfare Department website: http://www.swd.gov.hk/doc/family/ Overall Report (Part One).pdf. Accessed 20.11.2013.

9. Koenig MA, Stephenson R, Saifuddin A, Jejeebhoy SJ, Campbell J. Individual and contextual determinants of domestic violence in north India. American Journal of Public Health 2006; 96(1): 13238.

10. Linda T, Walker AJ. Gender in Families: Women and Men in Marriage, Work, and Parenthood, Journal of Marriage and the Family 1989; 51(4): 845-71.

11. Strauss MA, Gelles R, Clinard MB, Miere RF. Sociology of Deviant Behavior. Orlando, Florida; Harcourt College Publishers, 1989: 178-80.

12. Kraanen FL, Vedel E, Scholing A, Emmelkamp PM. Prediction of intimate partner violence by type of substance use disorder. J Substance Abuse Treat 2013; p ii: S07405472(13): 248-1.

13. Tsui KL, Chan AY, So FL, Kam CW. Risk factors for injury to married women from domestic violence in Hong Kong. Hong Kong Medical Journal 2006; 12(4): 289-95.

14. Knapp C. "HIV and Partner Violence: What are the implications for Voluntary Counseling and Testing?" Horizon Reports: Spring, 2001: 1-4. Http://www.popline. Org/node/179784. Accessed 20.11.2013.

15. Curran EG, Renzett CM. Theories of Crime, Boston USA: Allyn and Bacon, 1994: 100-3.

16. Dobash RE, and Dobash R. Violence Against Wives. New York: The Free Press, 1979: 106, 145-7, 150, 157.

17. Prevention of domestic violence Act, No. 34 of 2005, supplement to part II of the Gazette of the Democratic Socialist Republic of Sri Lanka, Colombo Sri Lanka: Department of Government Printing.

18. Section 21, Criminal Procedure Code, Act, No. 15 of 1979, of Sri Lanka, Colombo, Department of Government Printing. 